\title{
EXISTENCE THEORY AND STABILITY RESULTS FOR $\psi$-TYPE COMPLEX-ORDER IMPLICIT DIFFERENTIAL EQUATIONS
}

\author{
D. ViveK, S. K. Ntouyas, K. Kanagarajan and J. Prasanth
}

Abstract. This paper concerns the existence and stability results for $\psi$-type complex-order implicit differential equations with boundary conditions. The results are based on the Banach contraction mapping principle. An example is presented to illustrate the main results.

Mathematics subject classification (2010): 26A33, 34A08.

Keywords and phrases: $\psi$-fractional derivative, boundary value problems, implict differential equations, existence, stability.

\section{REFERENCES}

[1] R. Almeida, A Caputo fractional derivative of a function with respect to another function, Commun. Nonlinear Sci. Numer. Simul. 44 (2017), 460-481.

[2] O. Baghani, D. ViVeK, K. Kanagarajan, Theory of hybrid fractional differential equations with complex order, Sahand Communications in Mathematical Analysis 15 (1) (2019), 65-76.

[3] L. BYSZEWSKI, Theorems about the existence and uniqueness of solutions of semilinear evoluation nonlocal Cauchy problem, J. Math. Anal. Appl. 162 (1991), 494-505.

[4] E. M. Elsayed, K. Kanagarajan, D. ViveK, On the existence and stability of solution of boundary value problem for fractional integro-differential equations with complex order, Filomat 32 (8) (2018), 1-10.

[5] S. Harikrishnan, R.W. Ibrahim, K. Kanagarajan, On $\psi$-Hilfer fractional differential equation with complex order, Universal Journal of Mathematics and Applications 1 (1) (2018), 33-38.

[6] A.A. Kilbas, H.M. SRivastava, J.J. Trujillo, Theory and Applications of Fractional Differential Equations, in: North-Holland Mathematics Studies, vol. 204, Elsevier Science B.V., Amsterdam, 2006.

[7] V. Lakshmikantham, S. Leela, J. Vasundhara Devi, Theory of Fractional Dynamic Systems, Cambridge Scientific Publishers, 2009.

[8] L. LiU, J.R. WANG, D. O'Regan, Ulam-Hyers-Mittag-Leffler stability for $\psi$-Hilfer fractionalorder delay differential equations, Adv. Difference Equ. (2019), 2019:50.

[9] E.R. Love, Fractional derivatives of imaginary order, J. Lond. Math. Soc. (2) 2 (2-3) (1971), $241-$ 259.

[10] K.S. Miller, B. Ross, An Introduction to the Fractional Calculus and Differential Equations, John Wiley, New York, 1993.

[11] I. Podlubny, Fractional Differential Equations, Academic Press, San Diego, 1999.

[12] S. G. Samko, A.A. Kilbas O. I. Marichev, Fractional Integrals and Derivatives-Theory and Applications, Gordon and Breach Science Publishers, Amsterdam, 1993.

[13] J. Vanterler da C. Sous a, E. Capelas de Oliveira, A Gronwall inequality and the Cauchytype problem by means of $\psi$-Hilfer operator, Differ. Equ. Appl. 11 (1) (2019), 87-106.

[14] D. ViVeK, E. M. ElSAYED, K. KAnAGARAJAN, Existence and Ulam stability results for a class of boundary value problem of neutral pantograph equations with complex order, SEMA Journal, (2020).

[15] D. Vivek, K. Kanagarajan, S. Harikrishnan, Dynamics and stability results of fractional pantograph equations with complex order, Journal of Applied Nonlinear Dynamics 7 (2) (2018), 179187. 
[16] D. Vivek, K. Kanagarajan, S. Harikrishnan, Dynamics and stability results of fractional integro-differential equations with complex order, Discontinuity, Nonlinearity, and Complexity 7 (2) (2018), 119-127. 